\title{
Complete right cerebral hemispheric diffusion restriction and its follow-up in a case of Rasmussen's encephalitis
}

\author{
Farha Furruqh, ${ }^{1}$ Suresh Thirunavukarasu, ${ }^{2}$ Asthik Biswas, ${ }^{1}$ Ravichandran Vivekandan ${ }^{1}$
}

${ }^{1}$ Department of Radiology, ndira Gandhi Government General Hospital and Post Graduate Institute, Puducherry, India

${ }^{2}$ Department of Neurology, Indira Gandhi Government General Hospital and Post Graduate Institute, Puducherry, India

\section{Correspondence to}

Dr Suresh Thirunavukarasu, sureshy2001@rediffmail.com

Accepted 23 August 2015
CrossMark

\section{To cite: Furrugh $\mathrm{F}_{\text {, }}$} Thirunavukarasu $S$,

Biswas A, et al. BMJ Case Rep Published online: [please include Day Month Year] doi:10.1136/bcr-2015212256

\section{DESCRIPTION}

A 30-year-old man presented with generalised status epilepticus. Initial brain CT was normal (figure 1). His generalised seizures were controlled with antiepileptics. However, he continued to have left focal seizures. An MRI was performed showing diffuse T2 hyperintensity, oedema and high signal on diffusion-weighted imaging (DWI) with corresponding low signal on apparent diffusion

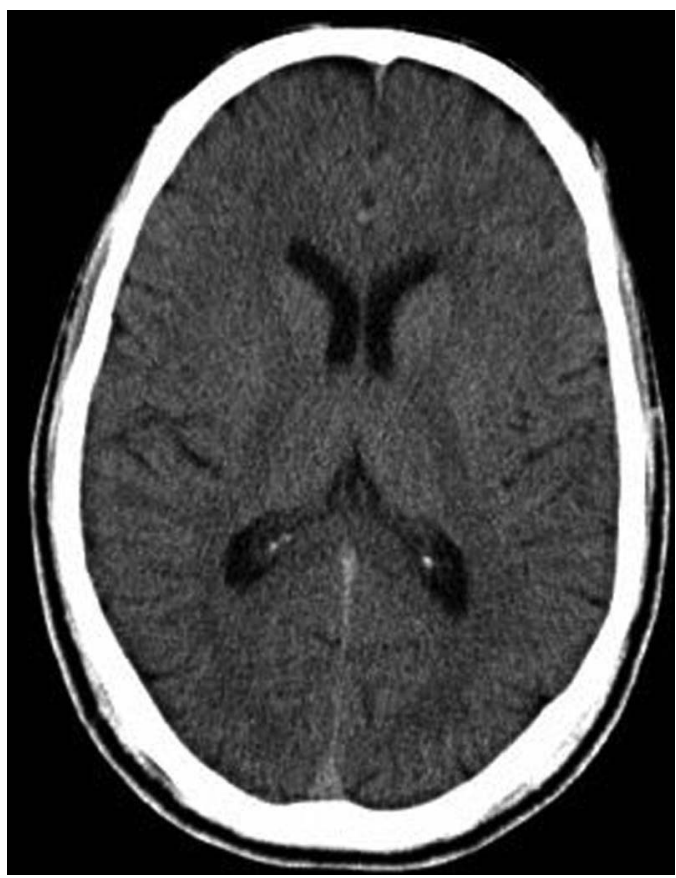

Figure 1 Normal brain CT at initial presentation. coefficient (ADC) maps in the entire right cerebral hemisphere, implying restricted diffusion (figure 2A-C). Cerebrospinal fluid (CSF) analysis showed raised protein at $70 \mathrm{mg} / \mathrm{dL}$ and increased lymphocytes in cell count. CSF PCR for herpes simplex virus was negative. A working diagnosis of hemispheric demyelination was performed. The patient responded to intravenous methylprednisolone and was continued on oral steroids for 2 months. $\mathrm{He}$ was able to walk at the time of discharge with a power of 4 plus on the left.

Five months later he returned in a state of unconsciousness, with left focal seizures. $\mathrm{He}$ also had a fever and productive cough. He had discontinued the antiepileptic drugs. A diagnosis of left focal status epilepticus with aspiration pneumonia and encephalopathy was performed. EEG showed slowing with sharp waves in the right cerebral hemisphere (figure 3). MRI showed diffuse right cerebral hemiatrophy with gliosis and high signal on ADC maps, suggestive of facilitated diffusion (figure $4 \mathrm{~A}-\mathrm{C}$ ). The imaging findings along with the clinical presentation and progression clinched the diagnosis of Rasmussen's encephalitis. The patient was treated with broad spectrum antibiotics and antiepileptic drugs. His sensorium improved but he had residual left hemiparesis on discharge with a power of $3 / 5$.

Rasmussen's encephalitis is a chronic progressive inflammatory disease of unknown aetiology, usually involving one cerebral hemisphere. Clinically, patients have abrupt onset of seizures with progressive neurological decline. ${ }^{1-3}$ Diagnosis can be performed on the basis of the clinical picture and neuroimaging demonstrating progressive cerebral hemiatrophy. ${ }^{3}$ Imaging in the acute phase may

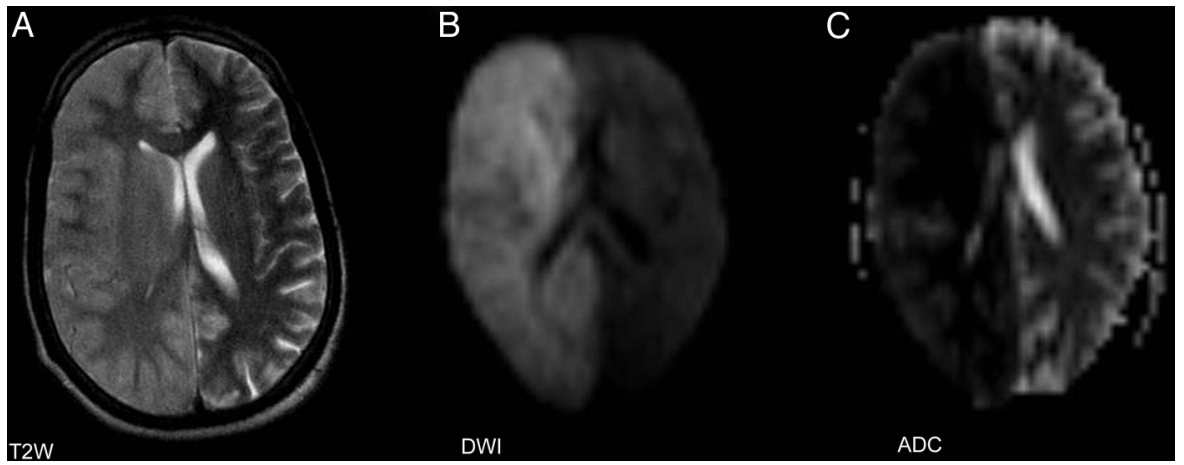

Figure $2 \mathrm{MRI}$ in the acute phase of illness, taken 4 days after the brain CT study. (A) Axial T2-weighted image showing diffuse hyperintensity and oedema of the right cerebral hemisphere. (B) Diffusion-weighted image showing diffuse hyperintensity in the right cerebral hemisphere. (C) Apparent diffusion coefficient (ADC) image showing diffuse hypointensity noted in the right cerebral hemisphere; findings in $B$ and $C$ indicate diffusion restriction. 


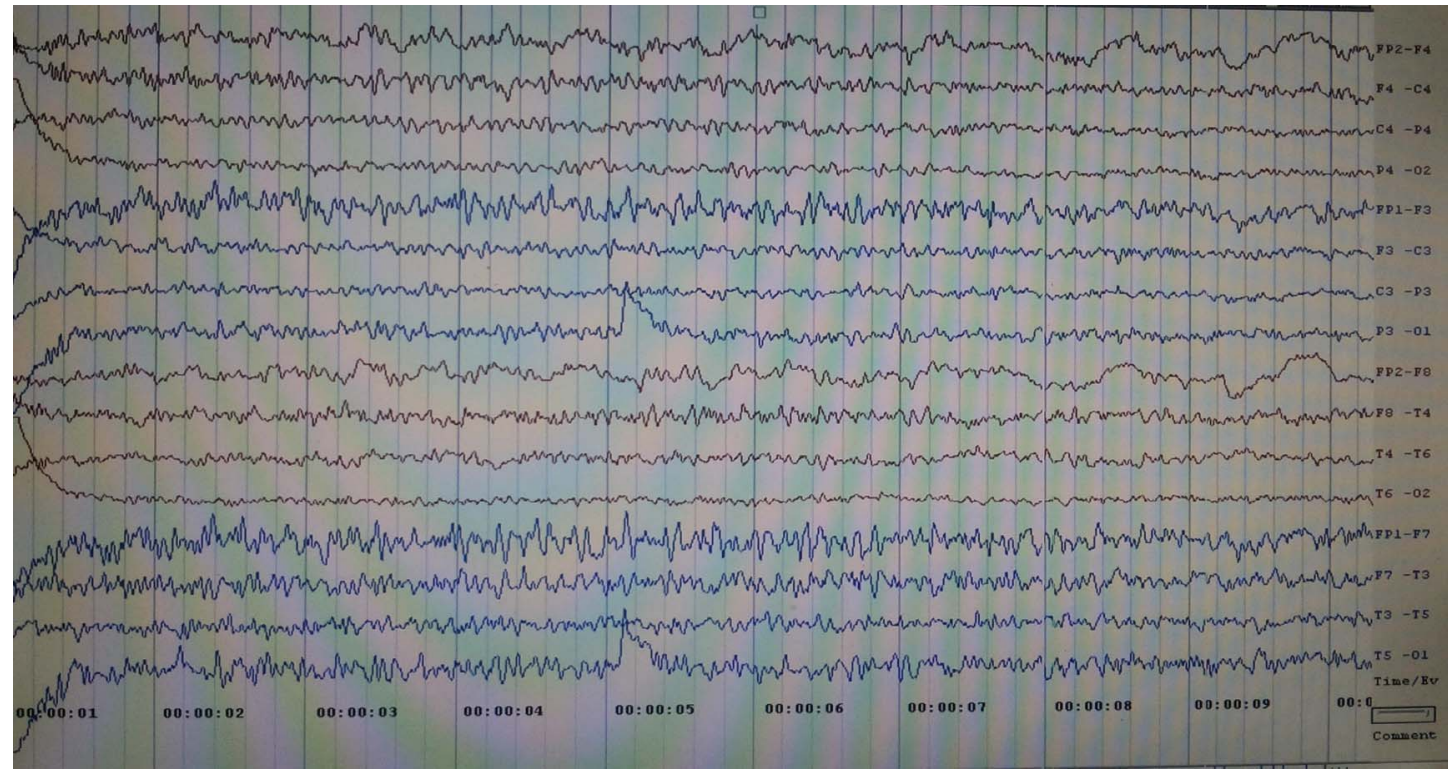

Figure 3 EEG during the late phase, showing slowing with sharp waves in the right cerebral hemisphere.

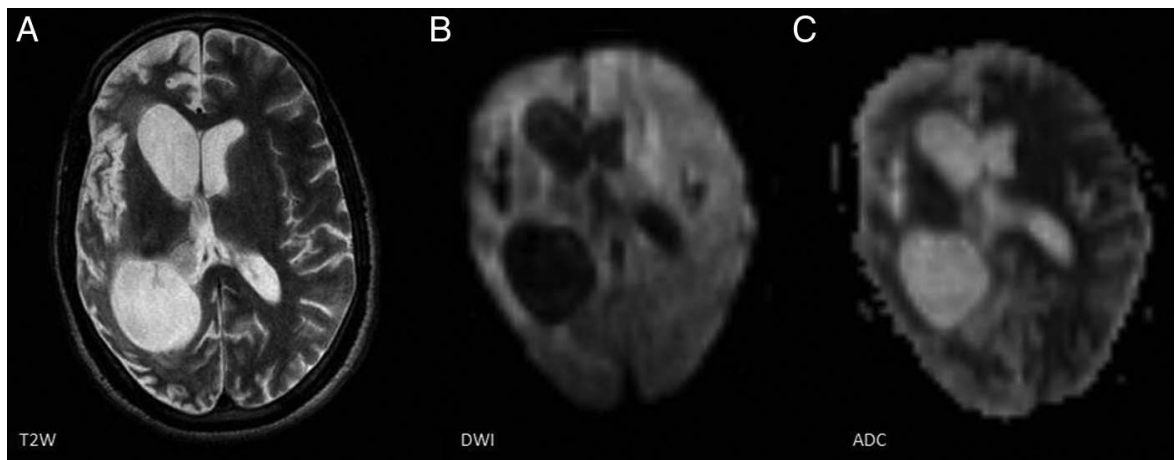

Figure $4 \mathrm{MRI}$ in the same patient 5 months later. (A) Axial T2-weighted image showing diffuse right cerebral hemiatrophy with gliosis. (B) Diffusion-weighted image showing subtle hyperintensity in the right cerebral cortex. (C) ADC (apparent diffusion coefficient) images showing hyperintensity in the right cerebral cortex; findings in B and C indicate increased diffusivity/facilitated diffusion, which corresponds with atrophy and gliosis.

reveal cerebral oedema. Cerebral atrophy, gliosis and facilitated diffusion are the classical features described with progression of the disease. ${ }^{4}$ These features were demonstrated in our case. However, complete right cerebral hemispheric diffusion restriction seen in the acute phase in our patient has not been previously reported, to the best of our knowledge. We aim to highlight this finding and offer an explanation for it.

DWI is a MRI technique that reflects the ability of water molecules to move freely in tissue. It reveals the molecular state of the tissue rather than giving a specific diagnosis. Restricted diffusion in an area implies that the motion of water molecules in that area is impeded as compared to normal. Restricted diffusion is seen as hyperintensity on DWI images, with corresponding area of hypointensity on ADC images. On the other hand, facilitated diffusion/increased diffusivity implies there is increased movement of water molecules. On imaging, it is seen as a variable signal intensity on DWI and increased signal intensity on ADC images. ${ }^{5}$

In our case, the finding of restricted diffusion in the acute stage can be explained on the basis of cytotoxic oedema, which impedes the free movement of water molecules. The finding of facilitated diffusion in the follow-up images is explained on the basis of atrophy and gliosis in the chronic stage of Rasmussen's encephalitis, which corresponds with the study of Sener. ${ }^{4}$

\section{Learning points}

- Rasmussen's encephalitis is a chronic progressive inflammatory disease of unknown aetiology, usually involving one cerebral hemisphere. Clinically, patients present with seizures and progressive neurological decline.

- Diagnosis can be performed on the basis of the clinical picture and neuroimaging. The finding of unilateral hemiatrophy in the appropriate clinical setting clinches the diagnosis.

- Diffusion restriction on MRI is typically associated with diagnosis of an acute infarct, however, it can also be seen in various other conditions. In our case, we attribute diffusion restriction to cytotoxic oedema in the acute phase of the illness, before the onset of atrophy.

- In the later phase, diffusion is facilitated, which corresponds with atrophy and gliosis. 
Contributors FF contributed to the concept, collection of data and drafting of the article. $A B$ helped in collection of data and in drafting the article. ST was the clinician in charge of the patient. He contributed to the diagnosis and management of the patient and reviewed the paper prior to submission. RV overlooked the drafting of the paper and reviewed the paper prior to submission. All the authors contributed to the diagnosis and reviewed the paper prior to submission.

Competing interests None declared.

Patient consent Obtained.

Provenance and peer review Not commissioned; externally peer reviewed.

\section{REFERENCES}

1 Geller E, Faerber EN, Legido A, et al. Rasmussen encephalitis: complementary role of multitechnique neuroimaging. AJNR Am J Neuroradiol 1998;19:445-9.

2 Bien CG, Widman G, Urbach H, et al. The natural history of Rasmussen's encephalitis. Brain 2002;125(Pt 8):1751-9.

3 Faria AV, Reis F, Dabus GC, et al. MRI findings in the diagnosis and monitoring of Rasmussen's encephalitis. Arq Neuropsiquiatr 2009;67:792-7.

4 Sener RN. Diffusion MRI and spectroscopy in Rasmussen's encephalitis. Eur Radiol 2003;13:2186-91.

5 Moritani T, Ekholm S, Westensson PL. Diffusion weighted imaging of the brain. 2nd edn. Berlin: Springer, 2009.

Copyright 2015 BMJ Publishing Group. All rights reserved. For permission to reuse any of this content visit http://group.bmj.com/group/rights-licensing/permissions.

BMJ Case Report Fellows may re-use this article for personal use and teaching without any further permission.

Become a Fellow of BMJ Case Reports today and you can:

- Submit as many cases as you like

- Enjoy fast sympathetic peer review and rapid publication of accepted articles

- Access all the published articles

- Re-use any of the published material for personal use and teaching without further permission

For information on Institutional Fellowships contact consortiasales@bmjgroup.com

Visit casereports.bmj.com for more articles like this and to become a Fellow 